\title{
Association of BDNF gene polymorphism with endophenotypes in posttraumatic stress disorder
}

\author{
(iD) Jun-Cheng Guo' \\ (iD) Xiang $L i^{2}$ \\ (iD) Min $\mathrm{GuO}^{3}$ \\ (iD) Yun-Suo Gao \\ (iD) Lin-Qiu Fu \\ D Xiang-Ling Jiang 6 \\ (iD) Lin-Mei Fu ${ }^{7}$ \\ (iD) Tao Huang
}

1. Central South University Xiangya School of Medical Affiliated Haikou Hospital, Haikou 570311, Hainan Province, China 2. The Third People's Hospital of Hubei Province, Wuhan 430060, P. R. China 3. Psychological Research Center of Hainan General Hospital, Haikou 570311, Hainan Province, China 4. Department of Equipment, Hainan General Hospital, Haikou 570311, Hainan Province, China 5. Department of Psychology, Hainan General Hospital, Haikou 570311, Hainan Province, China 6. Department of Clinical Laboratory, Hainan General Hospital, Haikou 570311, Hainan Province, China 7. Medical Center, Hainan General Hospital, Haikou 570311, Hainan Province, China

http://dx.doi.org/10.1590/1806-9282.66.5.615

\section{SUMMARY}

OBJECTIVE: To explore the association of brain-derived neurotrophic factor gene (BDNF) polymorphism with the latent cognitive endophenotype of posttraumatic stress disorder (PTSD) after major natural disasters in Hainan Province, China.

METHODS: A total of 300 patients with PTSD and 150 healthy controls (HC) were surveyed by psychoanalysis scale to assess their cognitive functions. Polymerase chain reaction (PCR) and polyacrylamide gel electrophoresis (PAGE) were used to detect the BDNF gene polymorphism.

RESULTS: In terms of the cognitive function, the scores in the PTSD group were worse than those of the HC group $(P<0.05$ or $P<0.01)$. There was a significant difference in the distribution of BDNF genotype and allele frequency between the two groups $(P<0.05)$. PTSD endophenotypes were significantly different among the BDNF genotypes in the PTSD group ( $P \leq 0.01)$.

CONCLUSION: There is a statistically significant difference in the polymorphism of BDNF gene between PTSD and HC groups, and the alleles are associated with the incidence of PTSD. Thus, it may be a risk factor for PTSD.

KEYWORDS: Stress disorders, post-traumatic. Endophenotypes. Polymorphism, genetic. Brain-derived neurotrophic factor.

\section{INTRODUCTION}

Epidemiological surveys have shown that 50-90\% of individuals have experienced at least one traumatic event in their lives, indicating that psychic trauma is one part of their life experiences. ${ }^{1}$ When people experience or witness the life-threatening disastrous events, including natural disasters (such as earthquakes, floods, typhoons, tsunamis, etc.), man-made disasters (such as war, terrorist attacks, serious traffic accidents, fires, mine accidents, rape, robberies, etc.), major loss (such as a sudden death of a loved one, bankruptcy, loss of liberty or an important position) and other traumatic events, they would 
endure tremendous suffering and feel terrified, fearful, helpless and other physical discomfort, leading to many serious consequences, and the most serious one is post-traumatic stress disorder. ${ }^{2}$

Few people know the neurocognitive function of post-traumatic stress disorder. There is also little literature on the executive function in patients with posttraumatic stress disorder (PTSD). We hypothesized that the incidence of PTSD is high and then attempted to determine the association of the executive function with PTSD on the basis of this hypothesis. In recent years, PTSD has become a new hot spot in the psychiatric department and psychological researches. However, there is still few understandings and researches on this field. ${ }^{3}$ Cognitive function may be a characteristic indicator of PTSD. However, at present, there is relatively few genetic researches on cognitive function in patients with PTSD in China. Therefore, we attempted to study whether PTSD patients have a wide range of cognitive dysfunction, such as damages in memory, visual breadth, verbal function, attention, executive function and other aspects, in order to study the endophenotypes of cognitive impairment in PTSD patients.

\section{METHODS}

\section{Subjects}

Clinician administered PTSD scale (CAPS), compiled by Blake et al. ${ }^{4}$., the National Center for Posttraumatic Stress Disorder, which was used as a structured interview diagnosis of PTSD.

CAPS methods were used to screen the subjects. Those in line with the inclusion criteria were grouped into the PTSD group. With the help of a psychiatrist, investigators conducted one-on-one interviews using the executive function questionnaire. All investigators had received unified training. The consistency of the observation was higher than $95 \%$. Unified guidance of the questionnaire was used to ensure integrity. Inclusion criteria for PTSD group included: 1. PTSD patients found in the epidemiological surveys of Hainan Province from October 2011 to July 2014; 2. aged 30-60 years; with a diagnosis of PTSD; 3 . in good physical health, and the informed consent was provided; 4. post-traumatic stress disorder diagnosed using CAPS. Inclusion criteria for the HC group were as follows: 1. siblings, classmates, neighbors or friends of those selected into PTSD group; 2. aged 30-60 years, without any cancer or other consuming disease; 3 . in good physical health, non-pregnant women, without genetic mental illness, and the informed consent was provided. Finally, there were 300 PTSD and 150 healthy controls meeting the corresponding criteria. This study was conducted in accordance with the declaration of Helsinki. This study was conducted with approval from the Ethics Committee of Hainan General Hospital. Written informed consent was obtained from all participants. Cognitive function scales included Hanoi tower (TOH), Wisconsin card sorting test (WCST), Trail making test (TMT) and Wechsler adult intelligence scale-revision by China (WAIS-RC).

Detection of brain-derived neurotrophic factor gene (BDNF) polymorphism

After the epidemiological survey and the scale assessment, all the subjects underwent $5-10 \mathrm{~mL}$ blood sample collection from the antecubital vein. The blood samples were anticoagulated with EDTA and stored at $-20^{\circ} \mathrm{C}\left(-4^{\circ} \mathrm{F}\right)$ at the Central Laboratory of People's Hospital of Hainan Province until use. Genomic DNA was extracted from the blood samples using whole blood genomic DNA extraction kit (OMEGA, USA). The concentration and purity of genomic DNA were determined, and both of them met the requirement of polymerase chain reaction (PCR) amplification. The primer pair specific to $B D N F$ gene was designed using Primer Premier 5.0 software. Primer pair for rs6265 locus: (forward) 5'-TTTCTCCCTACAGTTCCACCAG-3', (reverse) 5'-CTCCAAAGGCACTTGACTACTG-3', and the amplified product size was $343 \mathrm{bp}$. A total of 50 $\mu \mathrm{L}$ of the reaction system contained $1 \mu \mathrm{L}$ of genomic DNA, $1 \mu \mathrm{L}(10 \mu \mathrm{M})$ of each primer, $0.25 \mu \mathrm{L}(5 \mathrm{U} / \mu \mathrm{L})$ of pfu polymerase, $5 \mu \mathrm{L}$ of $10 \times$ Buffer $(200 \mathrm{mM}$ Tris $\mathrm{HCl}, \mathrm{pH}$ 8.8; 100 mM KCl; 20 mM MgSO4; 160 mM (NH4)2SO4; 1\% Triton, $1 \mathrm{mg} / \mathrm{mL}$ BSA), $1 \mu \mathrm{L}(10 \mathrm{mM})$ dNTPs and de-ionized water $40.75 \mu \mathrm{L}$. PCR amplification running conditions for rs6265 site included pre-denaturation at $98^{\circ} \mathrm{C}\left(208^{\circ} \mathrm{F}\right)$ for 3 minutes, 35 cycles of denaturation at $95^{\circ} \mathrm{C}\left(203^{\circ} \mathrm{F}\right)$ for 1 minute, annealing at $60^{\circ} \mathrm{C}\left(140^{\circ} \mathrm{F}\right)$ for 45 seconds, extension at $55^{\circ} \mathrm{C}\left(131^{\circ} \mathrm{F}\right)$ for 55 seconds, followed by extension at $72^{\circ} \mathrm{C}\left(162^{\circ} \mathrm{F}\right)$ for 8 minutes. PCR kit was purchased from Shanghai Jierui Biological Engineering Co., Ltd. The PCR products were sent to Sangon (Shanghai) Bioengineering Services Ltd. for sequencing.

\section{Statistical analysis}

Data were entered into epidata3.02 software by two persons individually, and then analyzed using SPSS v19.0 software. Data were presented as mean \pm 
standard deviation (SD). Mean of each parameter was calculated using Cohen's D value method. TOH, WCST, TMT and WAIS-RC scores between PTSD patients and healthy controls were compared using the independent sample t-test. ANOVA was used to compare the difference in each parameter among the genotypes of BDNF rs6265 in PTSD group. The test level was set as 0.05. Multiple regression analysis encodes genotypes $\mathrm{AA}, \mathrm{AC}$, and $\mathrm{CC}$ as 0,1 , and 2, respectively; and has a $\mathrm{Y}$ code of 0,1 , indicating no disease and disease. One line per patient. The SNP genotype is AA, genotype CC, genotype AC, and so on. The data can be saved into an excel file. When analyzing, use "data analysis", single factor analysis, select CASE as the result variable, and SNP as the risk factor, and automatically give the required form.

\section{RESULTS}

Demographic characteristics

There were 300 patients in the PTSD group, aged 18-65 years, with an average age of $39.2 \pm 6.3$ years, including 182 males and 118 females, 257 married and 43 unmarried. Health control group included 150

TABLE 1. COMPARISON OF ETI SCORES BETWEEN THE TWO GROUPS.

\begin{tabular}{l|l|l|l|l|l|l} 
Group & $\begin{array}{l}\text { Number of } \\
\text { cases }\end{array}$ & Intrusion & Avoidance & $\begin{array}{l}\text { High alert- } \\
\text { ness }\end{array}$ & Separation & $\begin{array}{l}\text { Total scores } \\
\text { of PTSD }\end{array}$ \\
\hline PTSD & 300 & $3.16 \pm 1.13$ & $3.97 \pm 1.52$ & $3.36 \pm 1.03$ & $2.16 \pm 0.94$ & $19.01 \pm 9.13$ \\
\hline Control & 150 & $4.73 \pm 1.19$ & $5.01 \pm 1.88$ & $4.15 \pm 1.21$ & $2.97 \pm 1.13$ & $25.23 \pm 8.43$ \\
\hline $\mathrm{t}$ & & 13.649 & 6.309 & 7.227 & 8.042 & 6.986 \\
\hline $\mathrm{P}$ & & $<0.001$ & $<0.001$ & $<0.001$ & $<0.001$ & $<0.001$ \\
\hline
\end{tabular}

Note: Data are shown as mean \pm SD

TABLE 2. COMPARISONS OF COGNITIVE FUNCTION SCORES BETWEEN THE TWO GROUPS.

\begin{tabular}{|c|c|c|c|c|c|}
\hline & Parameters & $\begin{array}{l}\text { Patients with } \\
\text { first-episode de- } \\
\text { pression }(n=300)\end{array}$ & $\begin{array}{l}\text { Healthy controls } \\
(n=150)\end{array}$ & $\mathrm{t}$ & p \\
\hline \multirow[t]{14}{*}{ WAIS-RC } & Knowledge & $9.98 \pm 1.93$ & $10.96 \pm 1.89$ & 5.112 & $<0.001$ \\
\hline & Comprehension & $10.59 \pm 2.04$ & $11.59 \pm 2.03$ & 4.910 & $<0.001$ \\
\hline & Arithmetics & $10.32 \pm 2.12$ & $10.75 \pm 2.70$ & 1.846 & 0.066 \\
\hline & Similarity & $10.30 \pm 2.18$ & $11.09 \pm 2.01$ & 3.718 & $<0.001$ \\
\hline & Digit span & $10.69 \pm 2.13$ & $11.20 \pm 1.75$ & 2.535 & 0.012 \\
\hline & Vocabulary & $9.89 \pm 2.01$ & $10.10 \pm 1.94$ & 1.057 & 0.291 \\
\hline & Digit symbol & $10.49 \pm 2.34$ & $10.21 \pm 2.20$ & 1.220 & 0.223 \\
\hline & Paint filling & $8.79 \pm 2.14$ & $9.01 \pm 2.03$ & 1.046 & 0.296 \\
\hline & Block pattern & $9.39 \pm 2.22$ & $10.89 \pm 2.15$ & 6.828 & $<0.001$ \\
\hline & Picture alignment & $9.75 \pm 2.36$ & $10.06 \pm 2.03$ & 1.374 & 0.170 \\
\hline & Object patching & $9.84 \pm 2.26$ & $11.06 \pm 2.13$ & 5.501 & $<0.001$ \\
\hline & Language intelligence & $99.77 \pm 12.56$ & $101.60 \pm 12.13$ & 1.474 & 0.141 \\
\hline & Operational intelligence & $97.39 \pm 12.09$ & $100.70 \pm 11.03$ & 2.817 & 0.005 \\
\hline & Total intelligence & $98.58 \pm 12.23$ & $101.15 \pm 11.66$ & 2.823 & 0.005 \\
\hline \multirow[t]{5}{*}{ M-WCST } & Number of sorting & $4.23 \pm 1.65$ & $4.79 \pm 1.39$ & 3.571 & $<0.001$ \\
\hline & Number of mistakes & $15.49 \pm 5.25$ & $13.30 \pm 4.21$ & 4.430 & $<0.001$ \\
\hline & Number of correctness & $31.76 \pm 6.32$ & $34.10 \pm 5.25$ & 3.910 & $<0.001$ \\
\hline & Number of continuous mistakes & $5.60 \pm 3.05$ & $4.60 \pm 3.02$ & 3.289 & $<0.001$ \\
\hline & Number of random mistakes & $8.09 \pm 3.29$ & $7.09 \pm 3.64$ & 2.932 & 0.004 \\
\hline \multirow[t]{3}{*}{$\mathrm{TMT}$} & A time-consuming $(\mathrm{s})$ & $52.40 \pm 11.14$ & $45.75 \pm 11.57$ & 5.893 & $<0.001$ \\
\hline & B time-consuming (s) & $80.75 \pm 12.12$ & $69.73 \pm 12.15$ & 9.085 & $<0.001$ \\
\hline & Interference & $28.39 \pm 3.62$ & $24.00 \pm 2.59$ & 13.250 & $<0.001$ \\
\hline \multirow[t]{3}{*}{$\mathrm{TOH}$} & Time for planning & $7.22 \pm 2.65$ & $5.92 \pm 2.60$ & 4.936 & $<0.001$ \\
\hline & Time for execution & $25.95 \pm 8.76$ & $18.69 \pm 7.11$ & 8.802 & $<0.001$ \\
\hline & Total & $33.17 \pm 10.15$ & $24.61 \pm 10.43$ & 8.327 & $<0.001$ \\
\hline
\end{tabular}

Note: Data are shown as mean \pm SD. 
TABLE 3. COMPARISONS OF COGNITIVE FUNCTION SCORES AMONG THE GENOTYPES OF BDNF RS6265 IN THE PTSD GROUP.

\begin{tabular}{|c|c|c|c|c|c|c|c|c|}
\hline & \multicolumn{3}{|l|}{ Genotype } & \multirow[t]{2}{*}{$\mathrm{F}$} & \multirow[t]{2}{*}{$P^{*}$} & \multirow[t]{2}{*}{$\mathrm{P} 1^{*}$} & \multirow[t]{2}{*}{ P2\# } & \multirow[t]{2}{*}{ P3\& } \\
\hline & $\mathrm{GG}(\mathrm{N}=93)$ & $\mathrm{GA}(\mathrm{N}=139)$ & $\mathrm{AA}(\mathrm{N}=68)$ & & & & & \\
\hline Key symptom scores & $11.22 \pm 3.21$ & $11.10 \pm 2.62$ & $10.40 \pm 2.36$ & 1.978 & 0.140 & - & - & - \\
\hline \multicolumn{9}{|l|}{ WAIS-RC } \\
\hline Knowledge & $10.01 \pm 1.94$ & $9.80 \pm 2.17$ & $10.31 \pm 2.51$ & 1.256 & 0.286 & - & - & - \\
\hline Comprehension & $10.29 \pm 2.48$ & $10.81 \pm 1.91$ & $10.55 \pm 2.11$ & 1.651 & 0.194 & - & - & - \\
\hline Arithmetics & $10.61 \pm 2.70$ & $10.39 \pm 1.92$ & $9.78 \pm 2.21$ & 2.792 & 0.063 & - & - & - \\
\hline Similarity & $10.02 \pm 1.85$ & $10.13 \pm 2.06$ & $10.77 \pm 2.19$ & 2.405 & 0.092 & - & - & - \\
\hline Digit span & $10.69 \pm 1.68$ & $10.91 \pm 2.09$ & $10.24 \pm 2.12$ & 2.616 & 0.074 & - & - & - \\
\hline Vocabulary & $8.97 \pm 2.71$ & $9.96 \pm 2.68$ & $11.01 \pm 2.54$ & 11.651 & $<0.001$ & 0.007 & $<0.001$ & 0.008 \\
\hline Digit symbol & $9.40 \pm 1.85$ & $10.86 \pm 2.37$ & $11.22 \pm 2.32$ & 16.967 & $<0.001$ & $<0.001$ & $<0.001$ & 0.302 \\
\hline Paint filling & $8.41 \pm 2.29$ & $8.82 \pm 2.32$ & $9.25 \pm 2.24$ & 2.658 & 0.072 & - & - & - \\
\hline Block pattern & $9.13 \pm 2.48$ & $9.26 \pm 2.37$ & $10.01 \pm 2.53$ & 2.918 & 0.056 & - & - & - \\
\hline Picture alignment & $9.46 \pm 2.37$ & $9.67 \pm 2.46$ & $10.31 \pm 2.34$ & 2.595 & 0.076 & - & - & - \\
\hline Object patching & $9.75 \pm 2.09$ & $9.69 \pm 2.02$ & $10.27 \pm 2.14$ & 1.921 & 0.148 & - & - & - \\
\hline Language intelligence & $102.20 \pm 13.65$ & $96.39 \pm 12.01$ & $103.36 \pm 12.70$ & 9.352 & $<0.001$ & $<0.001$ & 0.548 & $<0.001$ \\
\hline Operational intelligence & $94.34 \pm 11.94$ & $97.33 \pm 12.23$ & $101.68 \pm 11.84$ & 7.286 & $<0.001$ & 0.067 & $<0.001$ & 0.016 \\
\hline Total intelligence & $97.48 \pm 12.69$ & $98.86 \pm 12.01$ & $102.52 \pm 12.25$ & 3.448 & 0.033 & 0.403 & 0.013 & 0.042 \\
\hline \multicolumn{9}{|l|}{ M-WCST } \\
\hline Number of sorting & $3.84 \pm 1.64$ & $4.26 \pm 1.37$ & $4.70 \pm 1.52$ & 6.578 & 0.002 & 0.036 & $<0.001$ & 0.004 \\
\hline Number of mistakes & $16.83 \pm 6.19$ & $15.35 \pm 5.40$ & $13.94 \pm 4.60$ & 5.516 & 0.055 & $<0.001$ & $<0.001$ & 0.066 \\
\hline Number of correctness & $32.12 \pm 6.03$ & $32.04 \pm 5.75$ & $30.70 \pm 6.21$ & 1.406 & 0.247 & - & - & - \\
\hline Number of continuous mistakes & $6.64 \pm 3.80$ & $5.21 \pm 3.73$ & $4.97 \pm 3.04$ & 5.710 & 0.004 & 0.005 & 0.003 & 0.645 \\
\hline Number of random mistakes & $9.45 \pm 4.20$ & $7.55 \pm 3.72$ & $7.33 \pm 3.30$ & 8.773 & $<0.001$ & $<0.001$ & $<0.001$ & 0.679 \\
\hline \multicolumn{9}{|l|}{$\mathrm{TMT}$} \\
\hline A time-consuming $(\mathrm{s})$ & $52.64 \pm 9.79$ & $51.22 \pm 10.07$ & $53.52 \pm 11.12$ & 1.289 & 0.277 & - & - & - \\
\hline B time-consuming (s) & $83.32 \pm 13.80$ & $80.71 \pm 12.02$ & $77.05 \pm 11.34$ & 4.977 & 0.007 & 0.128 & 0.003 & 0.037 \\
\hline Interference & $28.75 \pm 5.71$ & $28.45 \pm 3.42$ & $27.78 \pm 3.25$ & 1.056 & 0.349 & - & - & - \\
\hline \multicolumn{9}{|l|}{$\mathrm{TOH}$} \\
\hline Time for planning & $7.52 \pm 2.59$ & $6.95 \pm 2.35$ & $7.36 \pm 2.12$ & 1.753 & 0.175 & - & - & - \\
\hline Time for execution & $27.81 \pm 7.13$ & $25.39 \pm 8.92$ & $24.55 \pm 8.53$ & 3.606 & 0.028 & 0.030 & 0.009 & 0.519 \\
\hline Total & $35.33 \pm 8.73$ & $32.34 \pm 9.71$ & $31.91 \pm 9.54$ & 3.625 & 0.027 & 0.017 & 0.019 & 0.764 \\
\hline
\end{tabular}

Note: Data are shown as mean \pm SD. ${ }^{*}$ Comparisons among genotypes GG, GA, and AA using one-way ANOVA; Comparisons between genotype GG and GA; \#Comparisons between genotype GG and AA; \&Comparisons between genotype GA and AA.

subjects, aged 26-64 years, with an average age of $41.75 \pm 9.14$ years, containing 79 males and 71 females, 132 married and 18 unmarried. There was no significant difference in age $(\mathrm{t}=-0.9532, \mathrm{P}=-0.3398)$, gender $\left(c^{2}=0.3721, \mathrm{P}=0.5412\right)$, marital status $\left(\mathrm{c}^{2}=1.623, \mathrm{P}=0.203\right)$ and education level $(12.65 \pm 5.72$ years $v s$. $\mathrm{l} 3.14 \pm 4.77$, $\mathrm{t}=0.4848, \mathrm{P}=-0.6288$ ) between the PTSD group and HC group. Total CAPS scores were $64.08 \pm 9.67$.

\section{Comparison of ETI scores}

Compared with the HC group, the scores of the symptoms such as intrusion, avoidance, high alertness and separation were significantly decreased and the total scores of PTSD were also reduced in the PTSD group $(\mathrm{P}<0.001$, Table 1$)$.

\section{Comparison of cognitive functions}

WAIS-RC scores showed that the scores of comprehension, similarity, block pattern, object patching, operational intelligence, total intelligence, and the parameters of M WCST, TMT and TOH tests in patients with first-episode depression were remarkably worse than those in the $\mathrm{HC}$ group $(\mathrm{P}<0.05$ or $\mathrm{P}<0.01$, Table 2).

Comparisons of cognitive function among the genotypes of BDNF rs6265

The cognitive function scores were compared among the genotypes of BDNF rs6265 in PTSD patients using variance analysis (Table 3 ). The results showed that the scores of vocabulary, digit symbols, 
language intelligence, paint filling, operating intelligence, total intelligence, B time-consuming (seconds), time for execution and total scores were prominently different among the three genotypes of BDNF rs6265 in PTSD patients $(\mathrm{P}<0.05)$. Then pairwise comparisons were carried out using Bonferroni method (the test level was 0.02). The scores of vocabulary and digit sign in genotype AA were markedly better than those in genotype GG $(\mathrm{P}<0.05)$. The language intelligence scores in genotypes $\mathrm{GG}$ and $\mathrm{AA}$ were superior to that in genotype $\mathrm{GA}(\mathrm{P}<0.05)$. The operating intelligence score in genotype GA was notably better than that in genotype GG $(\mathrm{P}<0.05)$. The overall intelligence in genotype $\mathrm{GA}$ was also superior to that in genotype GG $(\mathrm{P}<0.05)$. Except for the number of correctness, the other parameters of M-WCST were significantly different among the three genotypes $(\mathrm{P}<0.05)$. Furthermore, the time for execution of TOH in genotype GA was obviously better than that in genotype AA $(\mathrm{P}<0.05)$.

\section{DISCUSSION}

Endophenotype, proposed by Gottesman, is a description of an objective and measurable intermediate phenotype between genotypes and clinical phenotypes. ${ }^{5}$ The endophenotype is thought to be "detectable by biochemical tests or microscopy". It is a potential quantitative trait carrying genetic load and being indirectly associated with the typical behavioral symptoms of a disease as defined by DSM-IV or ICD10. Compared to the behavioral phenotypes, it has a closer relationship with the underlying genetic bases and can predict the likelihood of developing a particular disease. It is directly affected by gene effects and is thought to be determined by the genetic factors which are simpler than the disease phenotype. ${ }^{6}$ It can be measured physiologically, neurobiologically and cognitively. In theory, as compared by the disease itself, it is less affected by the genetic and environmental risk factors. Therefore, the effects of heterogeneity can be reduced in studying the roles of individual genes so that the results of the association studies of candidate genes can be more reliable. Moreover, it can discern all the problematic family members (including the unaffected members) in the pedigrees so that the genealogical statistics are more effective. It can also find out the potential biological difference of the disease (heterogeneity of the disease). Endophenotype is the middle part of the gene-to-disease pathways, which not only compensates for the huge gap between the genetic and disease processes but also helps to elucidate or modify the problematic pathophysiological basis of the disease.

Clinical observations found that psychic trauma caused by traumatic events is not the only factor that contributes to the occurrence and development of PTSD. There must be more risk factors that can explain the vulnerability of individuals to PTSD after trauma. Many studies have found that these risk factors include inheritance, family history, specific personality and coping styles, past traumatic experiences, past history of mental and behavioral problems, characteristics of parental relationships, the intensity of the impact of the experiencing life events just before the trauma, and other factors after the trauma, such as social support, exposure to subsequent stressors, etc. ${ }^{7}$ In addition, some studies have found that the intensity and number of discrete symptoms exhibited by an individual at the time of or just after a traumatic experience, the total number and overall severity of PTSD symptoms, are also the predictors of subsequent PTSD. According to domestic researches, the most important factor contributing to PTSD after the earthquake is the lack of post-disaster social supports rather than the exposure to stressors. For the earthquake-affected adolescents, the risk factors contributing to PTSD include the subjective perception of stressors, exposure level, sex (female), level of psychophylaxis and so on. ${ }^{8}$ In recent years, more and more studies have found that some risk factors act at a relatively low exposure level, while some factors act at a relatively high exposure level. Other factors such as family financial status, internal cohesion of family members, family coping styles and so on may also be related to the occurrence of traumatic stress disorder after the incident. In addition, timely post-traumatic social support and the corresponding psychological intervention for patients will reduce the incidence of PTSD. ${ }^{9}$ Until now, it remains unclear whether the risk factors for PTSD indicate a specific predisposition for PTSD or a general predisposition response of traumatic-induced mental disorders. However, the results of studies demonstrating the role of risk factors in the development of traumatic stress disorder suggest that the post-traumatic psychopathological response is neither a randomized process nor a result that can be completely determined by the nature of the traumatic event. Thus, as a result of an individual exposing to a traumatic event, the basic theoretical hypothesis that 
PTSD may potentially occur in any individual exposed to a traumatic event remains to be demonstrated by further studies.

According to the central dogma of Molecular Biology, genetic information is transmitted from DNA to RNA and then translated into proteins that express the function. ${ }^{10}$ If PTSD is associated with different genetic variations, each aberrant gene can cause a particular protein change and lead to a corresponding dysfunction. Even though the occurrence of PTSD may be related to multiple gene interactions and the interaction between genes and environmental factors, the corresponding dysfunctions caused by each pathogenic gene are generally identifiable. Without a given standard to determine the features of depression resulted from a single gene, the endophenotype of the disease can only be determined based on the findings and hypotheses in prior studies. It ranges from the clinical features, such as the melancholic temperament of the family members of PTSD patients, to the neurophysiological or neuropsychological measurements, brain areas with specific and important functions, and structural measurements of cerebral ventricles' sizes. PTSD genetic studies with important and representative endophenotypes especially emphasize the abnormalities of information processing, while more and more attention has been paid to the studies on the endophenotypes of cognitive dysfunction in PTSD. In the studies on the PTSD pathological endophenotypes, ${ }^{11}$ cognitive function was evaluated using neuropsychological test scores. Our results showed that the key symptom scores of BDNF rs6265 in PTSD patients with genotype AA were significantly higher than those in patients with genotype GA or GG. After further control with sex, age, course of disease and psychotic symptoms, there was a significant positive correlation between genotype AA and key symptom scores and a significant negative correlation between genotype GG and key symptom scores, suggesting that BDNF gene polymorphism is associated with depression endophenotype. Meanwhile, with regard to the endophenotype of cognitive function, the neuropsychological test scores except the amount of TMT interference showed significant differences among the three genotypes, ${ }^{12}$ which were all superior in genotype GG to AA. In particular, M-WCST items and the time-consuming results of TMT-A and TMT-B were the best in the patients with genotypes GG, followed by those with GA, and then those with AA, which were all statistically significant, suggesting that the polymorphism of $B D N F$ gene is related to the endophenotypes of cognitive function. The general cognitive function of the patients with genotype GG was superior to that in the patients with the other two genotypes, especially in the executive function, such as generalization, attention, working memory, cognitive transfer, visual discrimination, space perception, planning ability and so on, which were the worst in genotype AA. Our preliminary findings of the relationship between the BDNF polymorphisms and PTSD endophenotypes were consistent with foreign studies. ${ }^{13}$ Baig et al. ${ }^{14}$ conducted a controlled study on BDNF Val66Met (rs6265) gene polymorphisms in 203 schizophrenia patients and 133 healthy volunteers, and found that the working memory of the schizophrenia patients with BDNF Met/Met genotype were more severely damaged than those with BDNF Val/ Val. Functional magnetic resonance imaging (fMRI) was also used to study the hippocampal function of healthy volunteers when they were undergoing revised Webster adult memory scale (WMS-R) and WAIS detection. The results showed that the response of the bilateral hippocampus tails in patients with genotype $\mathrm{Val} / \mathrm{Met}$ was more abnormal than that in the patients with genotype $\mathrm{Val} / \mathrm{Val}$ and displayed a decrease in neurointegration. ${ }^{15}$ The researchers also found that such effects can affect the secretion and subcellular localization of BDNF by means of rat neuronal tissue culture. Therefore, it is speculated that the point mutation of Val to Met causes the structural change of BDNF molecule, resulting in the failure of normal BDNF transmission and secretion and then affecting memory formation and neuronal plasticity. ${ }^{16}$ Other studies agree that Met-transfected hippocampal neurons produce an inefficient transport of BDNF to secretory vesicles, thereby reducing the activity-dependent BDNF secretion and decreasing the cognitive functions such as performance and memory. ${ }^{17}$ There is a statistically significant difference in BDNF Val66Met polymorphism between PTSD patients and healthy volunteers. The Met allele is associated with the incidence of PTSD. It is a risk factor for PTSD. Its polymorphism is related to the endophenotype of PTSD. Patients with genotype Met/Met had more severe depression and more severe cognitive impairment than those with genotype $\mathrm{Val} / \mathrm{Val}$, especially in the executive functions, such as generalization, attention, working memory, cognitive transfer, visual discrimination, space perception and planning ability. 
In recent years. researchers have identified a large number of complex diseases/traits-associated genetic variants by performing genome-wide association studies (Genome-wide association studies, GWAS), which may provide important clues on understanding the mechanisms of related diseases. However, GWAS has its own limitations in terms of false positive and false negative results, very few SNPs located in the functional areas and insensitive to detect rare and structural variations, which results in the application limitation of this method.The polymerase chain reaction $(\mathrm{PCR})$ and polyacrylamide gel electrophoresis (PAGE) method were used to extract genomic DNA by whole-blood genomic DNA extraction kit. The concentration and purity were in accordance with PCR amplification requirements and became the identification of mental illness. The most effective strategy for causative genes is also used in the research and clinical diagnosis of complex disease susceptibility genes. Some foreign scholars studied the cognitive function of schizophrenia patients with BDNF Val$66 \mathrm{Met}$ and also found that the cognitive functions in patients with genotype $\mathrm{Val} / \mathrm{Val}$ are superior to those with genotypes Met/Met. ${ }^{18,19}$ However, the current studies on the relationship between the polymorphisms of $B D N F$ gene and cognitive functions were mostly focused on animal experiments, and less were found on their correlation with PTSD. ${ }^{20}$ Therefore, the conclusions of this study are yet to be further confirmed. ${ }^{21}$

In conclusion, this study investigated the cognitive function (inhibition, retrieval, working memory and planning) of PTSD, and found that the severe executive function of PTSD was consistent with the findings of PTSD patients caused by other causes. The results showed that the executive function of PTSD is impaired, which may mean abnormal changes of brain function and structure. PTSD is associated with neurocognitive impairment or linkage disequilibrium.

\section{Acknowledgements}

This work was funded by 2016 Hainan Priority Research and Development Plan (ZDYF2018227), National Natural Science Fund (81760255).

\section{Conflicts of interest}

The authors declare no conflict of interest.

\section{Authors contributions}

Jun-Cheng Guo and Xiang Li wrote the manuscript. Min Guo designed this paper and performed critical revision of the manuscript; Jun-Cheng Guo, Xiang Li and Yun-Suo Gao performed data collection; LinQiu Fu, Xiang-Ling Jiang, Lin-Mei Fu and Tao Huang analyzed the date. All authors read and approved the final manuscript.

\section{RESUMO}

OBJETIVO: Explorar a associação do polimorfismo do gene fator neurotrófico derivado do cérebro (BDNF) com o endofenótipo cognitivo latente de transtorno de estresse pós-traumático (TEPT) após grandes desastres naturais na província de Hainan, China.

MÉTODOS: Um total de 300 doentes com TEPT e 150 controles saudáveis (HC) foi investigado pela escala de psicanálise para avaliar as suas funções cognitivas. A reação em cadeia polimerase (PCR) e a eletroforese em gel de poliacrilamida (Page) foram usadas para detectar o polimorfismo do gene BDNF.

RESULTADOS: Em termos de função cognitiva, as pontuações no grupo TEPT foram piores do que as do grupo $H C(P<0,05$ ou $P<0,01)$. Houve uma diferença significativa na distribuição do genótipo de BDNF e frequência do alelo entre os dois grupos $(P<0,05)$. Os end-

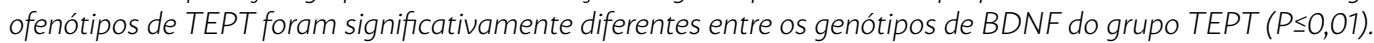

CONCLUSÃO: Existe uma diferença estatisticamente significativa no polimorfismo do gene BDNF entre o TEPT e os grupos HC, e os alelos estão associados à incidência do TEPT. Assim, pode ser um fator de risco para TEPT.

PALAVRAS-CHAVE: Transtornos de estresse pós-traumáticos. Endofenótipos. Polimorfismo genético. Fator neurotrófico derivado do cérebro.

\section{REFERENCES}

1. Guo JC, Tian ZL, Wang XD, Guo M, Li MY, Gao YS, et al. Post-traumatic stress disorder after typhoon disaster and its correlation with platelet 5-HT concentrations. Asian Pac J Trop Med. 2016;9(9):913-5.

2. McCarron KK, Reinhard MJ, Bloeser KJ, Mahan CM, Kang HK. PTSD diagnoses among Iraq and Afghanistan veterans: comparison of administrative data to chart review. J Trauma Stress. 2014;27(5):626-9.

3. Chen T, Guo M, Gao Y, Chen F, Guo J, Liu T, et al. A comparative study on the levels of serum cytokines and cortisol among post-traumatic stress disorder patients of Li and Han ethnicities in Hainan. Chin Med J (Engl). 2014;127(15):2771-4

4. Blake DD, Weathers FW, Nagy LM, Kaloupek DG, Gusman FD, Charney DS, et al. The development of a Clinician-Administered PTSD Scale. J Trauma Stress. 1995;8(1):75-90.

5. McGue M. Irving Gottesman and the concept of endophenotype. Am J Med Genet C Semin Med Genet. 2017;175(3):341-2. 
6. Carlberg L, Scheibelreiter J, Hassler MR, Schloegelhofer M, Schmoeger $M$, Ludwig B, et al. Brain-derived neurotrophic factor (BDNF)-epigenetic regulation in unipolar and bipolar affective disorder. | Affect Disord. 2014;168:399-406.

7. Li L, Li MX, Pan LH, Wang GM, Guo M, Fu LQ, et al. Comparative analysis of platelet $5-\mathrm{HT}$ concentrations in $\mathrm{Han}$ and Li patients with post-traumatic stress disorder. Genet Mol Res. 2016;15(3). doi: 10.4238/gmr.15038265.

8. Young G. PTSD in court II: risk factors, endophenotypes, and biological underpinnings in PTSD. Int J Law Psychiatry. 2017;51:1-21.

9. Belhadj-Tahar H, Vilamot B, Granberg M, Passamar M. Brain-derived neurotrophic factor (BDNF) as a predictive factor for post-traumatic stress disorder (PTSD). Eur Neuropsychopharmacol. 2014;24:S594-5.

10. Lee B, Shim I, Lee H, Hahm DH. Effect of oleuropein on cognitive deficits and changes in hippocampal brain-derived neurotrophic factor and cytokine expression in a rat model of post-traumatic stress disorder. J Nat Med. 2018;72(1):44-56.

11. Yahyavi ST, Zarghami M, Naghshvar F, Danesh A. Relationship of cortisol, norepinephrine, and epinephrine levels with war-induced posttraumatic stress disorder in fathers and their offspring. Braz | Psychiatry. 2015;37(2):93-8.

12. Wang T. Does BDNF Val66Met polymorphism confer risk for posttraumatic stress disorder? Neuropsychobiology. 2015;71(3):149-53.

13. Yang G, Vilamot B, Passamar M, Sadeg N, Belhadj-Tahar H. Pilot prospective study on BDNF (brain derived neurotrophic factor) as a predictive biomarker of the occurrence of PTSD (post traumatic stress disorder). J US-China Med Sci. 2015;12:12-9.
14. Baig BJ, Whalley HC, Hall J, Mclntosh AM, Job DE, Cunningham-Owens $D G$, et al. Functional magnetic resonance imaging of BDNF val66met polymorphism in unmedicated subjects at high genetic risk of schizophrenia performing a verbal memory task. Psychiatry Res. 2010;183(3):195-201.

15. Besnard A, Sahay A. Adult hippocampal neurogenesis, fear generalization, and stress. Neuropsychopharmacology. 2016;41(1):24-44.

16. Domschke K. Clinical and molecular genetics of psychotic depression. Schizophr Bull. 2013;39(4):766-75.

17. Zaba M, Kirmeier T, lonescu IA, Wollweber B, Buell DR, Gall-Kleebach DJ, et al. Identification and characterization of HPA-axis reactivity endophenotypes in a cohort of female PTSD patients. Psychoneuroendocrinology. 2015;55:102-15.

18. Kida S, Kato T. Microendophenotypes of psychiatric disorders: phenotypes of psychiatric disorders at the level of molecular dynamics, synapses, neurons, and neural circuits. Curr Mol Med. 2015;15(2):111-8.

19. Miller DR, Logue MW, Wolf El, Maniates H, Robinson ME, Hayes IP, et al. Posttraumatic stress disorder symptom severity is associated with reduced default mode network connectivity in individuals with elevated genetic risk for psychopathology. Depress Anxiety. 2017;34(7):632-40.

20. Su H, Tao I, Zhang |, Xie Y, Wang Y, Zhang Y, et al. The effects of BDNF Val66Met gene polymorphism on serum BDNF and cognitive function in methamphetamine-dependent patients and normal controls: a case-control study. J Clin Psychopharmacol. 2015;35(5):517-24.

21. Boccia M, Nemmi F, Guariglia C. Neuropsychology of environmental navigation in humans: review and meta-analysis of FMRI studies in healthy participants. Neuropsychol Rev. 2014;24(2):236-51. 